\author{
Vlasta ONDREJKA HARBULÁKOVÁ ${ }^{1}$ \\ Adriana EŠTOKOVÁ ${ }^{2}$ \\ Alena LUPTÁKOVÁ ${ }^{3}$
}

\title{
MATHEMATICAL EVALUATION \\ OF DELETERIOUS PROCESSES \\ OF FLY ASH-BASED CONCRETE IN PIPELINES
}

\begin{abstract}
Concrete performs well when exposed to various atmospheric conditions, water, soil, and many other chemical exposures. However, some chemical environments or even water can deteriorate high-quality concrete. Paper considers the usefulness of current fly ash concrete technology and prevention techniques, and advances a new approach for making concrete resist the deleterious effects of corrosion. This paper is focused on study of the durability of concrete materials based on two types of fly ashes which substitute 5 wt. $\%$ of cement in concrete mixture. Mathematical evaluation using correlation analysis was applied for assessment of deterioration of the concrete samples with fly ash of different origins. Experiment was done by measurements of elementary leached-out ions concentration $(\mathrm{Ca}, \mathrm{Si}, \mathrm{Fe}, \mathrm{Al}, \mathrm{Cu}$ and $\mathrm{Mn}$ ) and subsequently correlation analysis between the ions each other (in the same type of fly ash or between different types of fly ash respectively) and also correlation between ions concentrations and $\mathrm{pH}$ values of leachate. The correlation coefficient showed different mechanism of calcium and silicon ions leaching when comparing the concrete samples with fly ash from brown coal burning and samples with fly ash from black coal burning.
\end{abstract}

Keywords: corrosion, correlation analysis, concrete deterioration

\footnotetext{
${ }^{1}$ Corresponding author: Vlasta Ondrejka Harbul'áková, Technical University of Košice, Civil Engineering Faculty, Institute of Environmental Engineering, Vysokoskolska 4, 04200 Košice, SLOVAKIA, + 421 (055) 602 4269, vlasta.harbulakova@tuke.sk

2 Adriana Eštoková, Technical University of Košice, Civil Engineering Faculty, Institute of Material Engineering, Vysokoskolska 4, 04200 Košice, SLOVAKIA, + 421 (055) 6024265 , adriana.estokova@tuke.sk

3 Alena Luptáková, Slovak Academy of Science, Institute of Geotechnics, Watsonova 45, 04353 Košice, SLOVAKIA, + 421 (055) 792 2622, luptakal@saske.sk
} 


\section{Introduction}

Deterioration due to leaching occurs gradually in structures in long-term contact with water. As a calcium hydrate in concrete dissolves and migrates into water around the concrete structure, the concrete becomes porous.

This type of deterioration is known as "concrete deterioration caused by $\mathrm{Ca}$ leaching", it progresses very slowly compared to other deteriorations such as the alkali-aggregate reaction or chloride attack. Consequently, this deterioration has not generally been considered in the design of ordinary concrete structure. However, in the design of special concrete structure with their service life over a hundred years or more, this type of deterioration must be considered [1]. The assessment of the condition or health of pipeline systems is very difficult given that they are typically buried and therefore not readily accessible for visual inspection [2]. From a corrosion perspective, the sewage is no more corrosive than ordinary "fresh" water, i.e., water that is neither acidic nor alkaline. Wastewater is aerated in most parts of the wastewater system, at least where the biological reactions do not consume all the dissolved oxygen. In areas where waste water is not aerated, it produces much more corrosive conditions for many materials [3].

Recent research has shown the benefit of using coal fly ash in preventing corrosion damage and leaching of concrete. Reduced lower water/cement ratio, decreased drying shrinkage/cracking, and increased durability are all benefits of fly ash concrete. Coal is classified according to its heating value and according to the percentage of carbon it contains. For example, anthracite (stands for black coal) contains the highest proportion of pure carbon (about 86 to 98\%) and has the highest heat value ( 31400 to $36385 \mathrm{KJ} / \mathrm{kg}$ ) of all forms of coal [4]. All forms of coal also contain other elements presented in living organisms, such as sulphur and nitrogen, that are very low in absolute numbers but that have important environmental consequences when coals are used as fuels [4]. Lignite (stands for brown coal) is brownish-black in color and has a carbon content around $60-70 \%$, a high inherent moisture content sometimes as high as $75 \%$, and an ash content ranging from $6 \%$ to $19 \%$ compared with $6 \%$ to $12 \%$ for bituminous coal [5].

Because of a lack of standardized methods, different test methods have been used, and various parameters have been modified to evaluate the resistance of leaching. In this paper, based of correlation analysis, the closeness between the dissolved ions concentrations each other and ions concentration and $\mathrm{pH}$ changes values was calculated. The leaching processes of concrete was tested in disttiled water whereas was simulated in 5 consequence cycles. Concrete samples with 5 wt. \% of fly ash (FA) of different origins, incorporated as partial cement replacement, were used. 


\section{Material and Methods}

Concrete samples of two compositions were used for a leaching experiment since Portland cement in concrete mixtures was replaced by $5 \mathrm{wt}$. \% of fly ash of two origins (FA from black coal burning and from brown coal burning). The concrete samples with fly ash replacement from brown-coal burning, prepared and tested in the experiment, are marked as ENO while the concrete samples of cement replacement by fly ash from black-coal burning as TEKO, respectively. Concrete cylinder samples of a $32 \mathrm{~mm}$ diameter and $15 \mathrm{~mm}$ height were formed as a drilled core from concrete cubes $(150 \times 150 \times 150 \mathrm{~mm})$ using drilling mechanism STAM. The cylinder specimens were rid of impurity, treated to a constant weight and then immersed into distilled water ( $\mathrm{pH}$ value 6.25) to simulate a corrosion caused by leaching. The fly ashes were of different chemical compositions, so the aim of the leaching test was to study the durability of concrete materials based on the different fly ashes in order to determine a possibility of particular fly ash to be used in concrete pipelines' material.

Experiments ran in five consecutive cycles. Each of the cycle consists of the following steps: seven-day exposure of sample to a liquid medium, removal the sample from the liquid, two-day drying of samples at room temperature and afterwards removing of precipitations by little brush, and re-immersion of sample into the medium. The leaching process was manifested by dissolving the main cement matrix's components such as calcium, silicon, iron or aluminium compounds into the leachant. Concentrations of elementary ions in leachates after each experimental cycle were determined using X-ray fluorescence analysis (XRF). Besides leached-out concentrations, the $\mathrm{pH}$ of the liquid media was measured. The values of $\mathrm{pH}$ in leachates were measured after every 7-day exposition using a $\mathrm{pH}$ meter $\mathrm{PHH}-3 \mathrm{X}$ Omega.

The deterioration process of concrete samples was evaluated using statistical analysis. For the statistical evaluation, measured leached-out concentrations of $\mathrm{Ca}, \mathrm{Si}, \mathrm{Fe}, \mathrm{Al}, \mathrm{Cu}$ and $\mathrm{Mn}$ ions and $\mathrm{pH}$ of media were chosen as deterioration parameters. A statistical relationship between deterioration parameters was analysed as follows: a) dependency between leached-out concentrations of individual elements and $\mathrm{pH}$, and b) dependency between leached-out concentrations of elements each other in relation to the fly ash type.

In statistics, dependence refers to any statistical relationship between two random variables or two sets of data. Correlation refers to any of a broad class of statistical relationships involving dependency. Descriptive statistics is the discipline of quantitatively describing the main features of a collection of data [6]. Increase of the absolute value of the correlation coefficient $\left(R_{\mathrm{xy}}\right)$ is proportional to linear correlation. Information about two dimensional statistical data set gives correlation coefficient $R_{\mathrm{xy}}$ as is shown in Eq (1). 


$$
R_{x y}=\frac{n \sum_{i=1}^{n} x_{i} y_{i}-\left(\sum_{i=1}^{n} x_{i}\right)\left(\sum_{i=1}^{n} y_{i}\right)}{\sqrt{\left[n \sum_{i=1}^{n} x_{i}^{2}-\left(\sum_{i=1}^{n} x_{i}^{2}\right)^{2}\right]\left[n \sum_{i=1}^{n} y_{i}^{2}-\left(\sum_{i=1}^{n} y_{i}^{2}\right)^{2}\right]}}
$$

$R_{\mathrm{xy}}$ values are from the interval $\langle-1,1\rangle$. If $R_{\mathrm{xy}}=1$, the correlation is full linear, if $R_{\mathrm{xy}}=-1$, then the correlation is inversely linear and if $R_{\mathrm{xy}}=0$, the pairs of values are fully independent. Than degree of the correlative closeness is: medium, if $0.3 \leq\left|R_{\mathrm{xy}}\right|<0.5$; significant, if $0.5 \leq\left|R_{\mathrm{xy}}\right|<0.7$; high, if $0.7 \leq\left|R_{\mathrm{xy}}\right|<0.9$; and very high, if $0.9 \leq\left|R_{\mathrm{xy}}\right|$.

Correlation coefficient was for the purposes of our assessment obtained by the function "Pearson" in Microsoft Excel.

\section{Results and Discussion}

The measured concentrations of leached-out $\mathrm{Ca}, \mathrm{Si}, \mathrm{Fe}, \mathrm{Al}, \mathrm{Mn}$ and $\mathrm{Cu}$ ions in aqueous environment at the end of each cycle $\left(1^{\text {st }}-5^{\text {th }}\right.$ cycle $)$ are reported in Table 1 .

Table 1. Measured concentrations of selected chemical elements in leachates

\begin{tabular}{|c|c|c|c|c|c|c|c|}
\hline \multirow{2}{*}{ Element } & \multirow{2}{*}{ Sample } & \multicolumn{6}{|c|}{ Cycles } \\
\hline & & 0 & 1 & 2 & 3 & 4 & 5 \\
\hline \multirow{2}{*}{$\begin{array}{c}\mathrm{Ca} \\
(\mathrm{mg} / \mathrm{L})\end{array}$} & ENO & 55.6 & 45.2 & 197.8 & 88.5 & 256.9 & 90.6 \\
\hline & TEKO & 55.6 & 127.4 & 158.3 & 110.1 & 277.2 & 111.4 \\
\hline \multirow{2}{*}{$\begin{array}{c}\mathrm{Si} \\
(\mathrm{mg} / \mathrm{L})\end{array}$} & ENO & 0 & 119.3 & 439.8 & 283.6 & 521.2 & 378.8 \\
\hline & TEKO & 0 & 153.8 & 424.2 & 307.2 & 584.2 & 460.8 \\
\hline \multirow{2}{*}{$\begin{array}{c}\mathrm{Fe} \\
(\mathrm{mg} / \mathrm{L})\end{array}$} & ENO & 0 & 0 & 5.5 & 0 & 4.8 & 4.9 \\
\hline & TEKO & 0 & 0 & 4.5 & 0 & 0 & 6.5 \\
\hline \multirow{2}{*}{$\begin{array}{c}\mathrm{Al} \\
(\mathrm{mg} / \mathrm{L})\end{array}$} & ENO & 79.4 & 28.5 & 169.2 & 107.9 & 216.1 & 166.1 \\
\hline & TEKO & 79.4 & 39.8 & 192 & 118.1 & 215.9 & 205.4 \\
\hline \multirow{2}{*}{$\begin{array}{c}\mathrm{Mn} \\
(\mathrm{mg} / \mathrm{L})\end{array}$} & ENO & 36.6 & 47.2 & 25.4 & 21.8 & 25.9 & 29.6 \\
\hline & TEKO & 36.6 & 0 & 21.9 & 37.9 & 34.3 & 25.8 \\
\hline \multirow{2}{*}{$\begin{array}{c}\mathrm{Cu} \\
(\mathrm{mg} / \mathrm{L})\end{array}$} & ENO & 9.9 & 14.3 & 13.3 & 0 & 0 & 9.5 \\
\hline & TEKO & 9.9 & 0 & 0 & 0 & 11.8 & 10.7 \\
\hline
\end{tabular}

The results of measured initial $\mathrm{pH}$ and $\mathrm{pH}$ values during the leaching experiment (after $1^{\text {st }}, 2^{\text {nd }}, 3^{\text {rd }}, 4^{\text {th }}$ and $5^{\text {th }}$ cycle) are presented in the Table 2 . 
Table 2. Measured pH values of leachates (initial and after each cycle)

\begin{tabular}{|c|c|c|c|c|c|c|}
\hline \multirow{2}{*}{ Sample } & \multicolumn{7}{|c|}{ Cycles } \\
\hline & 0 & 1 & 2 & 3 & 4 & 5 \\
\hline TEKO & 6.25 & 8.01 & 8.27 & 8.49 & 8.24 & 8.12 \\
\hline ENO & 6.25 & 8.44 & 8.75 & 8.87 & 8.4 & 8.28 \\
\hline
\end{tabular}

Calculation was aimed at an investigation of possible correlation between the dissolved ions from the concrete matrix and increase/decrease in $\mathrm{pH}$ values. Correlation coefficient $\left(R_{\mathrm{xy}}\right)$ was calculated for both types of concrete samples (one set of samples with ENO fly ash cement replacement and one set with TEKO fly ash). Results that consider combination of results from Table 1 and 2 are presented in Table 3.

Table 3. Correlation coefficients of dependency between ions' leached-out masses and pH

\begin{tabular}{|c|c|c|}
\hline \multirow{2}{*}{ Correlated parameters } & \multicolumn{2}{|c|}{$R_{\mathrm{xy}}$} \\
& \multicolumn{2}{|c|}{} \\
\cline { 2 - 3 } & ENO & TEKO \\
\hline $\mathrm{Ca} / \mathrm{pH}$ & 0.39 & 0.54 \\
\hline $\mathrm{Si} / \mathrm{pH}$ & 0.70 & 0.75 \\
\hline $\mathrm{Fe} / \mathrm{pH}$ & 0.37 & 0.26 \\
\hline $\mathrm{Al} / \mathrm{pH}$ & 0.31 & 0.45 \\
\hline $\mathrm{Mn} / \mathrm{pH}$ & -0.39 & -0.21 \\
\hline $\mathrm{Cu} / \mathrm{pH}$ & -0.21 & -0.40 \\
\hline
\end{tabular}

No significant correaltion was found for the leached-out masses and $\mathrm{pH}$ exepting silicon $\left(R_{\mathrm{xy}}=0.7\right)$. This finding was not assumed especially for calcium since calcium is dissolved from cement matrix in form of calcium hydroxide thus the increasing trend in $\mathrm{pH}$ values of leachate was expected based on our previous studies aimed at fly ash-based concretes [7,8]. Calculated low dependency can be linked with the fact that after leaching, the calcium ions participated in chemical reactions in leachate resulting in new compounds formation as mentioned in [9].

In the next part, the relation between leachated-out ions of $\mathrm{Ca}, \mathrm{Si}, \mathrm{Fe}, \mathrm{Al}$, $\mathrm{Cu}$ and $\mathrm{Mn}$ in distilled water according to the types of used fly ash was studied. The correlations between various pairs of $\mathrm{Si}, \mathrm{Ca}, \mathrm{Fe}, \mathrm{Al}, \mathrm{Mn}$ and $\mathrm{Cu}$ ions leached-out for the same type of sample were determined and are presented in Table 4. 
Table 4. Correlation coefficients of leached-out ions between each other for TEKO and ENO samples

\begin{tabular}{|c|c|c|}
\hline \multirow{2}{*}{ Correlated parameters } & \multicolumn{2}{|c|}{$R_{\mathrm{xy}}$} \\
\cline { 2 - 3 } & ENO & TEKO \\
\hline $\mathrm{Ca} / \mathrm{Si}$ & 0.86 & 0.79 \\
\hline $\mathrm{Ca} / \mathrm{Fe}$ & 0.76 & -0.1 \\
\hline $\mathrm{Mn} / \mathrm{Cu}$ & 0.66 & 0.47 \\
\hline $\mathrm{Si} / \mathrm{Fe}$ & 0.85 & 0.44 \\
\hline $\mathrm{Si} / \mathrm{Mn}$ & -0.7 & 0.16 \\
\hline $\mathrm{Ca} / \mathrm{Cu}$ & -0.4 & 0.21 \\
\hline $\mathrm{Al} / \mathrm{Mn}$ & -0.76 & 0.4 \\
\hline $\mathrm{Fe} / \mathrm{Al}$ & 0.88 & 0.60 \\
\hline $\mathrm{Ca} / \mathrm{Al}$ & 0.87 & 0.60 \\
\hline
\end{tabular}

As shown in Table 4, a high correlation was found between dissolved $\mathrm{Ca}$ and $\mathrm{Si}$ for both the ENO samples with fly ash from brown coal burning (0.86) and TEKO samples with fly ash from black coal burning (0.79). High dependency was found also between leached-out $\mathrm{Fe} / \mathrm{Al}$ ions, between $\mathrm{Ca} / \mathrm{Al}$ ions and $\mathrm{Si} / \mathrm{Fe}$ for sample ENO $(0.7 \leq|\mathrm{Rxy}|<0.9)$; where for $\mathrm{Si} / \mathrm{Mn}$ the inverse high correlation was found out (also for ENO sample).

No correlation was calculated for TEKO samples $\mathrm{Ca} / \mathrm{Fe}, \mathrm{Si} / \mathrm{Mn}, \mathrm{Si} / \mathrm{Mn}, \mathrm{Si} / \mathrm{Cu}$ and $\mathrm{Ca} / \mathrm{Mn}$. For leached-out ions concentrations of $\mathrm{Fe} / \mathrm{Cu}$ no correlation was for both concrete types.

Consequently, a dependency in the individual elements was investigated comparing the leached-out masses of the same ions regarding the type of the concrete sample (Table 5).

As reported in Table 5, the correlation closeness of $\mathrm{Ca}, \mathrm{Si}$ and $\mathrm{Al}$ ions leached in distilled water was calculated as very high $(0.9,0.99$ and 0.98 , respectively) for both concrete samples while only a high correlation was found for Fe ions $\left(0.7 \leq\left|R_{\mathrm{xy}}\right|<0.9\right)$. The finding points to the similar individual mechamismus of leaching and behaviour of main components (calcium, silicon, and aluminium compounds) for both concrete samples even with the fly ashes of various compositions. The correlation found out between leached-out amounts of cuprum from the different types of concrete samples was found to be fully independent. In case of manganese the calculated correlation was high, but inverse. It means that the more massive was leaching from concrete samples with black coal the less massive was leaching from samples with brown coal. 
Table 5. Correlation coefficients of dependency of leached concentration of selected chemical elements

\begin{tabular}{|c|c|}
\hline Leached-out elements & $R_{\mathrm{xy}}$ \\
\hline $\mathrm{Ca}(\mathrm{ENO} / \mathrm{TEKO})$ & 0.90 \\
\hline $\mathrm{Si}(\mathrm{ENO} / \mathrm{TEKO})$ & 0.99 \\
\hline $\mathrm{Fe}(\mathrm{ENO} / \mathrm{TEKO})$ & 0.71 \\
\hline $\mathrm{Al}(\mathrm{ENO} / \mathrm{TEKO})$ & 0.98 \\
\hline $\mathrm{Mn}(\mathrm{ENO} / \mathrm{TEKO})$ & -0.74 \\
\hline $\mathrm{Cu}(\mathrm{ENO} / \mathrm{TEKO})$ & -0.29 \\
\hline
\end{tabular}

\section{Conclusion}

The deterioration of concrete samples with addition of fly ashes of two various compositions was studied in the paper. Leached-out masses of individual elements in distilled water and $\mathrm{pH}$ of leachants were chosen as deterioration parameters to be investigated using correlation analysis. The findings revealed:

- Surprisingly, no significant correlation was found for the leached-out masses and $\mathrm{pH}$ even for calcium.

- Very high correlation closeness of $\mathrm{Ca}, \mathrm{Si}$ and $\mathrm{Al}$ leached-out masses in distilled water points to the similar individual mechamismus of leaching or behaviour in leachate for both concrete samples even with the fly ashes of various compositions.

- The more massive was leaching of manganese from concrete samples with black coal the less massive was leaching from samples with brown coal.

The more detailed study taking into account the chemical composition of concrete samples and incorporated fly ashes is still in progress.

\section{Acknowledgements}

\section{This research has been carried out within the Grants No. 2/0145/15 and 1/0481/13 of the Slovak Grant Agency for Science.}

\section{References}

[1] Ikeda M., et al.: Influence of type of cement on Ca leaching from concrete using experimental acceleration method, 29th conference on our world in concrete and structures, 25-26 August, Singapore 2004.

[2] Bradshaw A.S., daSilva G., McCue M.T., Kim J., Nadukuru S.S., Lynch J., Michalowski R.L., Pour-Ghaz M., Weiss, J., Green R.A.: Damage detection and health Monitoring of buried concrete pipelines, Prediction and Imulation Methods for 
Geohazard Mitigation - Oka, Murakami \& Kimoto (eds)., Taylor \& Francis Group, London 2009.

[3] OD/Coating HRDS Manual Appendex A: Basics on corrosion in wastewater collection and treatmnet system: The Corroding Environments and Materials, web page: http://www.hrsd.com/pdf/Coatings\%20Manual/2011/APPENDIX\%20A.pdf.

[4] Available on web page: http://www.encyclopedia.com/topic/coal.aspx.

[5] Ghassemi A.: Handbook of Pollution Control and Waste Minimization, CRC Press, 2001, pp. 434.

[6] Kreyszig E.: Advanced Engineering Mathematics, John Wiley and sons, 10th edition, 2011.

[7] Ondrejka Harbulakova V., Estokova A., Purcz P., Luptakova A.: Correlation analysis as a method for concrete deterioration investigation, ICOCEE 2015, Nevsehir: Nevsehir Haci Bektas Veli University, 2015, pp. 943-949.

[8] Ondrejka Harbulakova V., Estokova A., Purcz P., Luptakova A.: Investigation of correlation of concrete corrosion parameters, SGEM 2015, Sofia: STEF92 Technology Ltd., 2015, pp. 447-454.

[9] Merida A, Kharchi F.: Pozzolan concrete durability on sulphate attack. Procedia Engineering, 114, 2015, pp. 832-837.

\title{
MATHEMATICAL EVALUATION OF DELETERIOUS PROCESSES OF FLY ASH-BASED CONCRETE IN PIPELINES
}

\begin{abstract}
S u m m a r y
Concrete performs well when exposed to various atmospheric conditions, water, soil, and many other chemical exposures. However, some chemical environments or even water can deteriorate high-quality concrete. Paper considers the usefulness of current fly ash concrete technology and prevention techniques, and advances a new approach for making concrete resist the deleterious effects of corrosion. This paper is focused on study of the durability of concrete materials based on two types of fly ashes which substitute $5 \mathrm{wt}$. \% of cement in concrete mixture. Mathematical evaluation using correlation analysis was applied for assessment of deterioration of the concrete samples with fly ash of different origins. Experiment was done by measurements of elementary leached-out ions concentration $(\mathrm{Ca}, \mathrm{Si}, \mathrm{Fe}, \mathrm{Al}, \mathrm{Cu}$ and $\mathrm{Mn}$ ) and subsequently correlation analysis between the ions each other (in the same type of fly ash or between different types of fly ash respectively) and also correlation between ions concentrations and $\mathrm{pH}$ values of leachate. The correlation coefficient showed different mechanism of calcium and silicon ions leaching when comparing the concrete samples with fly ash from brown coal burning and samples with fly ash from black coal burning.
\end{abstract}

Keywords: corrosion, correlation analysis, concrete deterioration

DOI:10.7862/rb.2016.169

Przestano do redakcji: 01.05.2016 $r$.

Przyjęto do druku: 28.06.2016 r. 